\title{
Das Lacunas e do Diálogo: as origens da tragédia na Grécia Antiga
}

\author{
Luciana da Costa Dias \\ Universidade Federal de Ouro Preto \\ Email: lucianacdias@yahoo.com.br
}

Resumo

Essa pesquisa tem por objetivo central discutir alguns pontos de confluência entre o teatro ocidental, em sua origem trágica, e o nascimento da filosofia, na Grécia dos séculos VI-IV a.C., a partir do fenômeno em comum da laicização da palavra e descoberta do diálogo (pautado na argumentação racional e na coesão do discurso), elementos marcantes do período. Para melhor clarificar esta relação, é necessário discutir conceitos como: mito e ritual, determinantes para o nascimento do teatro ocidental, e também o conceito de logos (ou razão), o qual, como se pretende alcançar, além de ligado às origens do pensamento filosófico, se relaciona também com a consolidação do fenômeno teatral no ocidente em sua forma trágica. $\mathrm{E}$, por último, pretende-se investigar também aspectos relativos à encenação das tragédias nos anfiteatros gregos.

Palavras-chave

Origens do Teatro. Tragédia Grega. Mito. Ritual. Nascimento da Filosofia.
Abstract

The main objective of this research is to discuss some points of convergence within the tragic origin of Western theatre and the birth of philosophy in Greece from the 6th to 4th Centuries BC. The starting point is the common phenomenon of word laicization and emphasis on dialogue (based on rational argumentation and the cohesion of discourse), striking characteristic of period. To clarify this relationship, it is necessary to discuss concepts such as myth and ritual, which were determinant for the birth of western theatre, and also the concept of logos (or reason), which is linked as well to the origins of philosophical thought and to the consolidation of the theatrical phenomenon in the West in its tragic form. Finally, we intend to investigate aspects related to the staging of tragedies in Greek amphitheatres.

Keywords

Origins of Theatre. Greek tragedy. Myth. Ritual. Birth of Philosophy. 
Queremos fazer do teatro uma realidade na qual se possa acreditar, e que contenha para o coração e os sentidos esta espécie de picada concreta que comporta toda sensação verdadeira. Assim como nossos sonhos agem sobre nós e a realidade age sobre nossos sonhos, pensamos que podemos identificar as imagens da poesia com um sonho, que será eficaz na medida em que será lançado com a violência necessária. E o público acreditará nos sonhos do teatro sob a condição de que ele os considere de fato como sonhos e não como um decalque da realidade; sob a condição de que eles lhe permitam liberar a liberdade mágica do sonho, que ele só pode reconhecer enquanto marcada pelo terror e pela crueldade. (ARTAUD, 2006, p.97)

Quando (...) se mergulha no passado, ultrapassando suas próprias vivências e recordações, conduzido por perguntas, mas também por desejos, esperanças e inquietudes, se confronta primeiramente vestígios, que se conservaram até hoje e que, em maior ou menor número chegaram até nós. (KOSELLECK, 2006, p.99).

\section{À guisa de Introdução}

No breve espaço deste texto, pretende-se investigar um pouco das origens e da evolução da tragédia na Grécia Antiga. Dada a extensão do universo trágico, não temos a pretensão de esgotá-lo, mas, antes, de realizar um recorte e buscar introduzir como algumas das mudanças assistidas no ambiente da polis parecem ter sido fundamentais para o aparecimento e desenvolvimento da tragédia desde o espaço sagrado do ritual em direção à argumentação e ao discurso racional - marco indelével do mundo ocidental. Por um lado, ao pensarmos o teatro em suas origens, se torna impossível dissociá-lo do mito, afinal a tragédia tem seu início com a representação ritualística dos mitos gregos. Seu objetivo, ao menos inicialmente, como coloca Grimal (1978, p.45), seria "levar à cena os acontecimentos lendários acerca dos heróis e dos deuses", vindo seu desenvolvimento a ser profundamente influenciada pelas transformações sociais que contextualizaram seu nascimento. Contudo, como procuraremos evidenciar aqui, por outro lado, filosofia e tragédia também não podem ser dissociadas em suas origens.

A filosofia (o pensamento argumentativo que se consolida com Platão e Sócrates) e o teatro (a espetacularização da palavra-diálogo em contraposição ao coro e sua cada vez maior separação do ritual) surgem juntos, se alterando e modificando mutuamente. Se pensarmos na grandeza de festivais como as Dionisíacas, concursos trágicos que ocorriam anualmente, entenderemos que só foram possíveis com o desenvolvimento das cidades que dominaram o cenário grego e também devido a outro fator de extrema importância, a laicização da palavra e do espaço público, ou ainda: da palavra tornada pública.

Estes elementos se mostram, de alguma forma, presentes nas obras dos grandes dramaturgos da Grécia antiga. O fenômeno da laicização, oriundo do pensamento filosófico, parece impresso nas obras teatrais com a mesma proporção em que vai se instaurando na cidade. De tal forma que nesta pesquisa, pretende-se identificar a ligação entre teatro e filosofia de acordo com a transformação que pode ser observada entre as obras de Ésquilo (525a.C-456a.C) e de Eurípedes (480 a.C-406 a.C), respectivamente o primeiro e o último tragediógrafo de que temos registro. Além disso, pretende-se pensar a palavra posta em cena em seu caráter espetacular, destacando-se os estudos recentes que apontam novos elemen- 
tos sobre a encenação das tragédias na Grécia antiga. Sobretudo a partir das últimas décadas do século XX, o papel da encenação, o próprio caráter espetacular da palavra vem sendo redimensionado. (EASTERLING e HALL, 2010)

Acerca do caráter espetacular dos mitos, Karen Armstrong nos diz que

A mitologia em geral é inseparável do ritual. Muitos mitos não fazem sentido separados de uma representação litúrgica que lhes dá vida, sendo incompreensíveis em um cenário profano. (ARMSTRONG, 2005, p. 09)

Em outras palavras, levando em consideração que é na representação (ou encenação) dos mitos que os rituais se davam, haveria uma relação entre a origem da teatralidade (esse impulso para o "teatral", para a construção de uma cena como a delimitação de um espaço e tempo específicos) e os rituais primitivos, aqui historicamente entendidos como as primeiras expressões cênicas. Na medida em que este "impulso teatral" inaugura uma temporalidade e espacialidade própria, calcada na encenação e na vivificação da encenação, remeteria à ação ritualística "primitiva", quando o tempo ritual era um "outro tempo", que se destinava a tirar o homem da esfera do cotidiano, leva-lo à presença dos deuses e do sagrado e assim (re-) significar o mundo. (ELIADE, 1989)

O teatro é tão velho quanto a humanidade. Existem formas 'primitivas' desde os primórdios do homem. (...) O xamã que é portador do deus, o dançarino mascarado que afasta os demônios, o ator que traz vida à obra do poeta - todos obedecem ao mesmo comando, que é a conjuração de uma outra realidade, mais verdadeira. (BERTHOLD, 2010, p. 01)

Se formos mais longe no tempo, em dire- ção às origens do teatro grego, se mostra que o teatro tem origem nos cultos da população rural a divindades da vegetação - sobretudo em honra a Dionísio, sem esquecer dos mistérios órficos - que foram trazidos para o interior do espaço urbano. As Dionisíacas Rurais, por exemplo, englobavam um conjunto de rituais realizadas em honra ao deus Dionísio afim de garantir fertilidade à terra. Nessas festas eram realizadas danças, cantos e sacrifícios ao deus em busca da fertilidade. Com o crescimento da urbanização das cidades gregas (pólis), essa sociedade inicialmente agrícola começou a sofrer alterações políticas, sociais e culturais. As festas que inicialmente eram uma passagem de Dionísio para abençoar a colheita tornou-se o mais importante festival $A$ Grande Dionisíaca ou também chamado de Dionisíaca Urbana. Inicialmente ele se tratava apenas de uma transferência dos rituais realizados no meio rural para o urbano, mas com o passar do tempo ele se transformou em e um concurso de ditirambos tragédias e comédias com a duração de seis dias. Mas antes da institucionalização do teatro, havia já um caráter teatral que marcavam as festividades e os rituais.

Como coloca Margoth Berthold,

A história do teatro europeu começa aos pés da Acrópole, em Atenas, sob o luminoso céu azul-violeta da Grécia, (...) nos rituais de sacrifício, dança e culto. Para a Grécia homérica isso significava os sagrados festivais báquicos, menádicos, em homenagem a Dionísio, o deus do vinho, da vegetação e do crescimento, da procriação e da vida exuberante. Seu séquito é composto por Sileno, sátiros e bacantes. Os festivais rurais da prensagem do vinho, em dezembro, e as festas das flores de Atenas, em fevereiro e março, eram dedicados a ele. As orgias desenfreadas dos vinhateiros áticos honravam-no, assim como as vozes alternadas dos ditirambos e das 
canções báquicas atenienses. Quando os ritos dionisíacos se desenvolveram e resultaram na tragédia e na comédia, ele se tornou o deus do teatro. (BERTHOLD, 2010, p. 103)

Apesar destas considerações gerais iniciais, que fique claro que o que queremos destacar aqui é o outro lado deste processo - a outra face da moeda. Este impulso para o teatral, inicialmente religioso e mítico, encontrará sua laicização na Grécia entre os século VI e IV a.C., momento em que isso que chamamos de teatro ocidental tem sua origem, com a Tragédia e a Comédia que assim se instituem nas festividades urbanas da Atenas do período. As mudanças que podem ser observadas desde o ditirambo até o texto trágico em sua evolução, parecem refletir mudanças muito mais amplas que vinham tendo lugar no mundo antigo. A Grécia entre os séculos VI e IV a.C. pode ser considerada o berço não só do teatro ocidental como também da filosofia, o que não deixa de ser, no mínimo, curioso por suscitar uma série de questões e inter-relações que merecem ser investigadas. Iremos aqui, a partir deste aporte teórico, desdobrar alguns aspectos formais da tragédia e sua evolução ao longo dos tragediógrafos de que hoje se tem registro. Marquemos essa parte: da maior parte das tragédias produzidas no período clássico, somente umas tantas são ainda conhecidas. O conhecimento que temos da tragédia é marcado por lacunas e indícios.

Indícios que parecem indicar uma trilha, a qual tentaremos seguir. Não haveria nada de inédito em apenas afirmar que "o teatro é fiIho da cidade", parodiando a célebre citação de Pierre Vernant (2002) sobre o nascimento da filosofia. Afinal, é assunção corrente que a celebração cênica se "emancipa do culto" e se afirma no mundo grego enquanto fenômeno urbano, quando da migração dos rituais agrários em honra a Dionísio para a cidade-estado de Atenas, ocorrida oficialmente durante o governo do tirano Psístrato, em 534 a.C. É preciso, porém, entender como isto foi possível, na medida em que tal transformação é dependente de mudanças paradigmáticas de visão de mundo que vinham se processando desde o final do período arcaico. E mais que isso: neste momento, o teatro parece vir a ser também espelho do modo como os cidadãos pensavam e viam a si mesmos, trazendo em seu cerne as tensões e os conflitos em jogo no espaço urbano grego, que se consolidava.

\section{Teatro e Filosofia}

Como observa Vernant (2002, p. 48), acerca da polis, a cidade-estado grega: "a palavra deixa de ser o termo-ritual, a fórmula justa, e se torna o debate, a discussão, a argumentação, o diálogo". Será dentro do mesmo contexto, na cidade-estado de Atenas, considerada "centro cultural e político do mundo antigo", que filosofia e teatro progressivamente surgem e se consolidam. Não se trata de coincidência, mas sim, de dois lados do mesmo processo, como enfatizado por Kaufmann (1992). Neste sentido, como também coloca Jaeger em sua Paideia (2011, p. 483), há uma dependência inquestionável entre tais expressões culturais e o contexto político da cidade-estado: "A cultura grega fora, desde o primeiro instante, inseparável da vida da polis. E esta ligação não fora em nenhum lugar tão estreita como em Atenas".

É ponto marcante: a cidade grega não só representa o espaço onde as relações humanas 
puderam se constituir em forma democrática, graças à preeminência da palavra e a eclosão do diálogo, como também, ela mesma, é espaço que se constitui e consolida a partir destas instâncias. Observamos, assim, que a Grécia no período clássico viveu um fenômeno de radicalização da palavra, sintoma de uma transformação entre dois modos de vida, ou entre duas percepções distintas da realidade.

A polis, espaço urbano por excelência, viu a poesia - que, como Jaeger (2011) coloca, era o "centro da educação aristocrática agrária anterior" - ter seu lugar revisitado. A palavra do poeta (que em seu canto, "verdade revelada de inspiração divina", relembrava e mantinha vivo "aquilo que não podia ser esquecido") tivera papel fundamental na sociedade grega mais antiga. Por toda a Grécia arcaica, como coloca Detienne (1988), os poetas foram os "mestres da verdade", os grandes mestres e detentores do conhecimento, da palavra inspirada, ritualisticamente declamada. Eram os senhores de uma visão mítica de mundo, que começou a ser modificada. Ou seja, o processo racional que descambou na laicização da palavra em todas as instâncias, atingiria a própria visão poético-mítico-arcaica de mundo grego, que se transformaria radicalmente dentro do espaço urbano, através da vida na polis.

No entender de Vernant e Vidal-Naquet (1991, p. 08-09):

Com a cidade, desenvolve-se um sistema de instituições e um comportamento propriamente político. (...) É nítido o contraste social que a polis substituiu juntamente com as práticas e a mentalidade que lhes eram solidárias. Não é diferente com a tragédia. Ela não poderia refletir uma realidade que, de alguma forma, lhe fosse estranha.
Quando a verdade passa a se constituir a partir da persuasão, da argumentação e da racionalidade, elementos que se tornam a chave da vida política na cidade grega, surge a palavra dialogada, "lógica", até mesmo, em último grau, palavra sofística. Essa é a mudança radical que a Grécia viu acontecer e que imprimiria sua marca no mundo ocidental de modo indelével. Deu-se assim o advento de uma situação histórica inédita, caracteristicamente marcada pelo conflito entre duas mentalidades ou visões de mundo: de um lado, o mundo arcaico, mítico, da palavra revelada e das limitações do homem frente ao divino; do outro, a mentalidade clássica nascente, já a querer pôr o homem no centro.
À medida que as transformações so- ciais iam sendo acompanhadas de novos ideais quanto ao caráter e à conduta do ser humano, os poetas pu- deram eles mesmos alterar, corrigir ou expurgar a teologia homérica e hesió- dica [...]. De um modo geral, foram os [primeiros] filósofos que influenciaram os poetas [trágicos], pois foram eles que fizeram incidir uma crítica racional sobre uma teologia que se atribuía aos primeiros poetas. (CORNFORD, 1989, p. 236)

Neste ensejo, até mesmo a famosa crítica aos poetas de Platão, presente em sua República, muitas vezes erroneamente acusada de censura, pode ser melhor entendida. Como coloca Kaufmann (1992), é a atitude de um rival e não a de um censor. Sendo ele, de certa forma, um poeta e dramaturgo em si mesmo, Platão cria, em seus diálogos, textos ricos em imaginação e em falas persuasivas, ao longo das quais Sócrates (quase um personagem!) vem a expor o erro de seus interlocutores e tem suas ideias racional e encadeadamente expostas. Cornford (1989) destaca, na obra 
já citada, que o jovem Platão teria chegado, inclusive, a escrever tragédias, as rasgando e destruindo todas, porém, após conhecer Sócrates. Já Jaeger (2011) enfatiza que a preocupação de Platão é pedagógica: o que ele propõe é a necessidade de parâmetros racionais (ou melhor seria dizer "ideais"), que norteiem a poesia e as artes e, por consequência, a educação dos cidadãos ideais para a cidade. $\mathrm{O}$ que não podemos ignorar é que esta suposta "rivalidade" entre poetas e filósofos não começou com Platão. Não podemos esquecer que estamos falando de um momento em que as próprias fronteiras entre poesia e filosofia ainda estavam sendo demarcadas.

A crítica platônica se insere no bojo deste movimento maior, inédito, e que teve início na Grécia: o da laicização da palavra, não mais revelada pelo poeta em seu canto, mas alvo de discussão na Ágora. As fronteiras aí eram tênues, a ponto de Aristóteles, no começo de sua Poética, ao elencar os diferentes tipos de poesia imitativa, enquanto demarca a diferença entre a poesia dramática (da qual fazem parte a tragédia e a comédia) e a épica, representada pela epopeia, mencionar brevemente "a arte que utiliza o simples verbo, quer metrificado, quer não", de caráter tão amplo que nela ele inclui tanto "os diálogos socráticos" e quanto aqueles que ele denomina de "fisiólogos", e que nós hoje denominado de "Pré-socráticos" e que, por isso mesmo é de outro tipo, não se encaixando plenamente dentre as categorias demarcada (1447b).

Somado a isso, como Kaufmann (1992, p.01) coloca, "muitas da amplamente compartilhadas assunções sobre tragédia falham em se encaixar em algumas das melhores tragédias gregas, é porque, assim como a filosofia, a tragédia não pode ser referida como uma única entidade". Isso se dá porque as tragédias, ao longo do século $V$ a.C. são um todo em evolução, refletindo uma época de grandes mudanças.

Quando investigamos a origem e evolução do espetáculo trágico, tudo se torna ainda mais nebuloso. Se é assunção comum que os aspectos cênicos da tragédia teriam surgido a partir dos cultos da população rural, sobretudo em honra a Dionísio, que ganharam nova forma quando trazidos para o interior do espaço urbano, o como isso se deu é discutível. O ritual teria sido nitidamente revisitado pelas questões e processos que lá se davam, com a crescente incorporação de texto dialogado pelos atores aos elementos cênicos que o compunha, ainda que continuasse fortemente marcado não apenas pelo ritmo e pela gestualidade, mas inseparável da melopeia (o acompanhamento musical) e do uso de máscaras.

Não podemos esquecer que, como coloca Edith Hall (2008) a tragédia se desenvolveu com base em uma cultura do canto, fortemente poética. Originalmente, nas festividades em honra a Dionísio, "o canto do coro constituía a questão principal até que surgiu a interrupção de um narrador, cujo relato por fim se elevou às figuras efetivas da ação dramática." (Hegel, 2004, p.251) Em um esforço para promover o esplendor das festividades públicas, Psístrato convidou Téspis em 534 a.C. para se apresentar nas Dionisíacas, trazendo algo que até então não podia ser considerada "mais do que um embrião dentro do rito, que se desenvolveria mais tarde na tragédia" (BERTHOLD, 2010, p. 104-105). A partir do coro ditirâmbico, este assumiu papel destacado, supostamente representando o próprio Dionísio em meio ao coro de dançarinos-cantores dos ditirambos. Ao se destacar do coro, Téspis passaria a ser 
considerado, pelo menos oficialmente, como o primeiro "ator", o primeiro protagonista.

\section{Das ausências}

Chegamos assim a uma das muitas lacunas que cercam nosso conhecimento acerca do teatro grego antigo - do qual apenas três autores conhecemos os textos. Refletir sobre a história do teatro grego é refletir sobre a ausência. Como colocam Stearling e Hall (2008, p. XIX), "Muito embora o teatro como instituição e prática tenha encontrado um lugar no centro dos estudos clássicos, o ator antigo, bem como as técnicas de encenação, permanece fenômenos evasivos e relativamente pouco examinados".

Não são precisos os dados que preenchem o vazio entre Téspis e Ésquilo, o primeiro dos três grandes escritores de tragédias do mundo antigo de que hoje ainda temos registro. Entre a primeira apresentação de Téspis e o êxito de Ésquilo, passar-se-iam cerca de 60 anos anos de violentas disputas políticas que consolidaram a democracia ateniense. De algum modo, a tragédia parece se desenvolver em paralelo à democracia grega - essa mesma democracia que garantia a todos que fossem considerados cidadãos a isonomia e ao direito à palavra. A palavra, antes do poeta, depois do sofista e do orador brilhante será, neste intermédio, posta em cena no anfiteatro grego. Será a Ésquilo - que "abraçou apaixonadamente o conceito democrático da polis" (como sua tragédia, Eumênides, ao louvar o tribunal do Areópago, exemplifica) - que a "tragédia deve sua consolidação artística" (BERTHOLD, 2010, p. 106). O que sabemos: com Ésquilo, alguns dos principais cânones da encenação trágica foram estabelecidos, a começar pela adoção de dois atores em cena: o protagonista e o deuteragonista, separados do coro.

Com isso, Ésquilo reduziu a anterior importância do coro, tornando possível o diálogo entre personagens. É provável que tenha também introduzido aperfeiçoamentos no vestuário e nos cenários, a julgar pela dificuldade técnica de algumas de suas encenações. A presença de dois atores em contraposição ao coro - e não mais apenas um - trará mais riqueza ao espetáculo trágico, agora calcado no diálogo e com uma exposição cada vez maior de argumentos. Posteriormente, Sófocles, porá em cena um terceiro ator, o tritagonista, para conferir maior dinamismo às cenas, recurso utilizado posteriormente também por Ésquilo na Orestéia. Sófocles aumentou ainda mais os diálogos dos personagens e reduziu as falas do coro, embora tenha aumentado o número de seus componentes. É neste sentido que alguns eruditos sustentam que teria sido com Sófocles que a tragédia grega atingiu sua perfeição formal.

A presença de um número maior de atores traz a reboque a perda do lugar de destaque do coro e a consequente ênfase na ação, agora individual, centrada na figura do herói trágico. Nesse sentido, como coloca Hegel (2004, p.214), "o diálogo se tornará a forma dramática por excelência". É através do diálogo que os conflitos vêm a ser apresentados no teatro grego, permitindo que estes sejam experienciados pela assistência em seus diferentes aspectos.

O drama ("ação" em grego) trágico se construirá tanto sobre conflitos individuais quanto sobre conflitos de poder, dilacerando o indivíduo frente ao horizonte que se abre. O homem grego é então um homem em crise, neste sentido, por excelência trágico, dividido entre 
o mundo arcaico (do sangue e do genos familiar) e o Estado, entre o individual e o coletivo, entre as antigas leis dos deuses e as leis dos homens, entre a palavra mítica e a palavra racional. As personagens trágicas acabam por serem representantes desse momento de transição em sua tensão, sempre pagando um alto preço.

A Grécia Antiga foi um momento em que o teatro teve um papel na cidade como nunca dantes e como nunca depois: no espaço da polis grega, o ritual cênico que na Grécia teve origem veio a se dessacralizar cada vez mais, em direção à laicização e preeminência da palavra. Neste sentido, a filosofia (representativa do pensamento argumentativo que se consolida com Platão e Sócrates) e o teatro (a dramatização progressiva da palavra-diálogo em contraposição ao coro e assim sua cada vez maior separação do ritual) parecem nascer juntos: ainda que sigam caminhos tão opostos: são filhos da cidade, são filhos de todas as novas configurações humanas e sociais que nascem com a cidade - transformações estas que irão constituir a ambos de modo indelével.

Finalizamos o presente artigo com a certeza que este é apenas o vislumbre de um caminho, não seu pleno percurso. Em outro viés, poderíamos lembrar que o equilíbrio que Nietzsche verá na tragédia, entre o "apolíneo" e o "dionisíaco" - entre a clareza apolínea, presente no diálogo, e a contradição dionisíaca, representada pelo coro, originalmente de sátiros - é um equilíbrio frágil. Para ele, é isso que explicaria, de certo modo, a curta vida da tragédia grega que, em seu apogeu, duraria não mais que 75 anos ao longo, principalmente, do século $\mathrm{V}$ a.C. O século seguinte seria o século da filosofia e da plena presença da palavra racional que, em sua crítica, ele sintetiza na figura de
Sócrates e justamente por isso, em sua interpretação do fenômeno trágico, seria também este o momento da decadência da tragédia.

\section{Referências}

ARMSTRONG, Karen. Breve história do Mito. São Paulo: Cia das letras, 2005.

ARTAUD, Antonin. O teatro e seu duplo. São Paulo: Martins Fontes, 2006.

BERTHOLD, Margot. História Mundial do Teatro. São Paulo: Perspectiva, 2010.

BORNHEIM, Gerd. "Breves observações sobre o sentido e a evolução do Trágico", in $O$ Sentido e a Máscara. São Paulo, Perspectiva, 2007.

BRANDÃO, Junito de Souza. Teatro Grego: Tragédia e Comédia. Petrópolis: Vozes, 2009.

CORNFORD, F. M. Principium Sapientiae: as origens do pensamento filosófico grego. Lisboa: Fundação Calouste Gulbenkian, 1989.

DELEUZE, G. e GUATTARI, F. O que é a filosofia? Rio de Janeiro: Editora 34, 1992.

DETIENNE, Marcel. Os Mestres da Verdade na Grécia Arcaica. Rio de Janeiro: Jorge Zahar Editor, 1988.

EASTERLING, P.; HALL, E. Atores Gregos e Romanos. São Paulo: Odysseus Editora, 2010.

ELIADE, Mircea. Aspectos do mito. Lisboa: Edições 70, 1989.

ÉSQUILO, SÓFOCLES, EURÍPEDES e ARISTÓFANES. Teatro grego. [seleção, introdução, notas e tradução direta do grego por Jaime Bruna]. São Paulo: Cultrix, s/d. 
EURÍPIDES. Bacas. Tradução de JAA Torrano. São Paulo, Editora Hucitec, 1995.

Recebido: $11 / 08 / 2017$

GAZOLLA, Rachel. "Tragédia Grega: A Cidade Faz Teatro". Revista Philosophica, 2003, n. 26.

GRIMAL, Pierre. O teatro Antigo. Lisboa:Edições 70,1978

HALL, Edith. "Os atores-cantores da antiguidade". In: HALL, E.; EASTERLING, P. (orgs) Atores gregos e romanos. Sao Paulo: Odysseus, 2008.

HEGEL, G. W. F. Cursos de Estética. Tradução de Marco Aurélio Werle. São Paulo: EDUSP, 2004, vol. IV.

JAEGER, Werner. Paidéia. São Paulo: Martins Fontes, 2011.

KAUFMANN, Walter A. Tragedy and Philosophy. New Jersey: Princeton University press, 1992.

KITTO, H.D.F. A Tragédia Grega Lisboa: Almedina, 1990 (vol. I e II).

KOSSELECK, Reinhart. Espaço e Experiência e horizonte expectativa: duas categorias históricas Futuro Passado: Contribuição à semântica dos tempos históricos. Rio de Janeiro: Contraponto, 2006.

PLATÃO. A República. Lisboa. Fundação Calouste Gulbenkian, 2001.

VERNANT, Jean-Pierre e VIDAL-NAQUET, Pierre. Mito e tragédia na Grécia antiga. São Paulo: Brasiliense, 1991.

VERNANT, Jean-Pierre. As origens do pensamento grego. Rio de Janeiro: Difel, 2002. 